\title{
Factors Affecting Stress among Faculty Members of Public Universities in the Philippines: A Multiple Regression Analysis
}

\author{
Jeryl Shawn T. Tan ${ }^{1}$ \\ ${ }^{1}$ Department of Psychology, University of the Philippines Diliman, Quezon City, Philippines \\ Correspondence: Jeryl Shawn T. Tan, Department of Psychology, University of the Philippines Diliman, Quezon \\ City, Philippines. Tel: 632-9-28-2728. E-mail: jttan1@up.edu.ph
}

Received: July 9, 2017

Accepted: July 30, 2017

Online Published: August 7, 2017

doi:10.5539/ijps.v9n3p64

URL: http://doi.org/10.5539/ijps.v9n3p64

\begin{abstract}
This study focused on particular demographic and education-related factors that contribute to the stress levels of public university faculty members in the Philippines. Participants in this study were part-time or full-time faculty members of Philippine public universities and were teaching at least a class during the First Semester of Academic Year 2016-2017. Participants were tasked to answer a survey, online or paper format, consisting of 3 instruments and other questions. Responses from 100 participants were then analyzed with multiple regression as the main statistical analysis. Results showed part-time/full-time status, age, job satisfaction and negative religious coping as significant predictors of faculty stress. Other performed analyses also revealed significant negative correlations between job satisfaction and stressors related to reward and recognition and departmental influence. In addition, though faculty members preferred positive religious coping as a coping strategy over negative religious coping, a significant positive correlation was noted between the 2 types. Recommendations were made for future studies related to stress among public university faculty members in the Philippines.
\end{abstract}

Keywords: faculty stress, public university faculty members, positive religious coping, negative religious coping, multiple regression analysis

\section{Introduction}

\subsection{Faculty Stress}

In the field of industrial-organizational psychology, work stress is considered as a reaction to stimuli in a job that leads to negative consequences to the people who are exposed to them (Muchinsky, 2007). Much of the research on work stress has focused on the teaching profession in a university. Gmelch, Wilke, and Lovrich (1986) defined faculty stress as the faculty member's anticipation of his/her inability to respond sufficiently to a perceived demand, accompanied by the expectancy of negative consequence/s due to the insufficient response to work demand/s. Stress is a common phenomenon for all university faculty across all disciplines (Gmelch et al., 1986). The academic functions of university faculty are comprehensive, which include teaching and mentoring students, preparing papers and presentations for both class lectures and research conferences, attending to the needs of one's college or department/institute and so on. They also have to deal with functions outside the academic setting: their family life, social life and other commitments. Given the numerous roles and responsibilities, the intense demands and the high expectations set to them, many university faculty experience significant levels of stress and have shown particular responses to stress, such as increased turnover intent, decreased job performance, decreased job satisfaction, increased anxiety and increased depression (Reevy \& Deason, 2014; Winefield \& Jarrett, 2001; Blix, Cruise, Mitchell, \& Blix, 1994; Veena, Pushpalatha, \& Mallaiah, 2016; Khan, Aqeel, \& Riaz, 2014).

\subsection{Factors of Faculty Stress}

Researches indicate several factors that affect the stress levels of university faculty members. These include work overload (Thorsen, 1996; Abbas \& Roger, 2013; Gupta, Rao, \& Mukherjee, 2015), work-life imbalance, (Slišković \& Maslić Seršić, 2011; Kinman \& Jones, 2008; Rafeeq \& Harish, 2015), decreased job satisfaction (Brewer \& McMahan-Landers, 2013; Reevy \& Deason, 2014; Chung, 2011), increased number of students to teach (Easthope C. \& Easthope G., 2000; Jamison \& Enrera, 2015; Gartia \& Sharma, 2013), lack of university funding, resources and recognition (Gillespie, Walsh, Winefield, Dua, \& Stough, 2001; Reevy \& Deason, 2014; Gupta et al., 2015) and lack of administrative and colleague support (Slišković \& Maslić Seršić, 2011; Kavitha, 
2012; Gupta et al., 2015). Other demographic and education-related factors such as gender (Blix et al., 1994; Donovan, 2012; O’Laughlin \& Bischoff, 2005; Hart \& Cress, 2009; Greene et al., 2008; Gappa, 1987), academic ranks (Kinman, 2001; Arnold, Trice, Rosevear, \& McKinnon, 1996; Colacion-Quiros \& Gemora, 2016; Donovan, 2012), age (Lindholm \& Szelényi, 2009; Gmelch et al., 1986; Akbar \& Akhter, 2011; Merchant \& Shastri, 2013) and years of teaching experience (Merchant \& Shastri, 2013; Schuldt \& Totten, 2008; Gartia \& Sharma, 2013) also contribute to their stress levels.

There are also studies that investigated on the stress levels of university faculty members in the Philippines. De Cadiz and Sonon (2012) noted the stress levels of 30 faculty members of Eastern Visayas State University-Carigara Campus. Their conclusions included no significant differences in all interested variables, including age, sex, academic rank, length of service and field of specialization, due to their normal levels of stress, high levels of confidence and high levels of stress tolerance. However, they also concluded that the mastery of their fields of specialization was the best predictor in assessing their stress levels. Betonio (2015) reported moderate levels of stress related to Economic-related and School's Policies and Management Practices stresses but low levels of stress for Work and Peer-related and Family-related stresses among faculty members of La Salle University in Ozamiz City, Misamis Occidental. Examining data collected among faculty members from 12 Colleges of Pharmacy in Metro Manila, Loquias and Sana (2013) found that stress had a significant negative correlation with job satisfaction and was one of the two variables that significantly explained $33.7 \%$ of the variation in job satisfaction using stepwise regression. With a sample of 55 faculty members of West Visayas State University-Janiuay Campus, the study of Colacion-Quiros and Gemora (2016) revealed a significant difference in the stress level for academic rank but no significant differences for the variables age, sex, civil status and number of academic units. Dela Peña (2011) studied the relationship of spirituality level and work stress among education professors in Cagayan De Oro City. No significant relationships were found between work stress and the variables age, gender, educational attainment, length of teaching experience and spirituality. However, the author recognized the practical importance of spirituality in decreasing their work stress based on in-depth interviews.

\subsection{Religious Coping}

Religious coping, one of the most common coping strategies, is defined as the use of religious beliefs and practices in the facilitation of problem solving in order to easily adapt and to prevent or alleviate the negative emotional effects of the stressful situation (Pargament, Smith, Koenig, \& Perez, 1998). The use of religion was shown to help Filipino workers such as fast-food chain workers (Ereno et al., 2014) and policemen (Inasoria, 2014) in decreasing their work stress and in improving their job performance. Pargament, Feuille, and Burdzy (2011) identified two types of religious coping: positive religious coping involves "a secure relationship with a transcendent force, a sense of spiritual connectedness with others, and a benevolent force" (p. 51), while negative religious coping tackles spiritual stresses with the individual, with others and with God. This type includes religious coping methods, such as punishing God reappraisals (ex. feeling punished by God), demonic reappraisals (ex. feeling that the devil is involved in the stressor), spiritual discontent (ex. expressing dissatisfaction with God's relationship to the individual) and interpersonal religious discontent (ex. expressing dissatisfaction with the relationship with the church/clergy to the individual).

\subsection{Research Objectives and Questions}

Considering the teaching profession as one of the most stressful professions (Wiggins, 2015) and the lack of financial resources allocated to around 700 public universities and colleges/higher education institutions in the Philippines (Note 1; Conchada \& Zamudio, 2013; Ngohayon \& Nangphuhan, 2016; Commission on Higher Education [CHED], n.d.), the study's objectives were to assess the stress levels of public university faculty members in the Philippines and to identify significant predictors of their stress using multiple regresson analysis. This study, in particular, included positive and negative religious coping as possible predictors of faculty stress. According to a 2015 report by WIN/Gallup International, $86 \%$ of Filipinos interviewed consider themselves as religious (Akkoc, 2015). As such, the researcher was also interested to see if faculty members also apply religiosity as a source of strength and comfort in their way of coping with stress. Besides the two types of religious coping, the following variables were also featured: age, gender, part-time/full-time status, job satisfaction, years of teaching experience in a public and/or private university, number of students being taught/handled for all classes for the current semester (Note 2), number of different subjects being taught/handled for the current semester and number of teaching/class hours per week for all classes for the current semester. These variables were chosen based on findings from previous researches and suggestions from few faculty members the researcher was able to ask. The following questions were of interest for this study: 
- Is faculty stress related to each of the predictors? (Are these explanatory variables significant predictors of faculty stress?)

- Is an increase in stressors associated to time constraints and/or student interaction related to a decrease in job satisfaction? (Do time constraints and/or student interaction subscale/s have significant negative correlations with job satisfaction?)

- Is faculty stress decreased for faculty members who report using positive religious coping and vice-versa?

\section{Method}

2.1 Design

For this study, a correlational research design (with the survey method as the tool) was used in order to determine the degree of relationship between variables. With the aim of identifying significant predictors of faculty stress, the study's independent variables/predictors included the two types of religious coping and the aformentioned demographic and education-related factors, while the dependent variable was faculty stress.

\subsection{Sample}

In order to participate in this study, participants must be (1) a part-time or full-time faculty member of a public university in the Philippines during the First Semester of AY 2016-2017 and (2) teaching at least a class (ex. lecture, laboratory, physical education) in a public university in the Philippines during the First Semester of AY 2016-2017. A total of 106 faculty members participated in this study. However, six responses were not included in all analyses as much of the questions were not answered. After checking the distribution (skewness) of each variable, it is worth noting that during the semester majority of the participants had a full-time status, taught two to four subjects and did not employ negative religious coping at all (i.e., received the lowest possible score for negative religious coping in the Brief RCOPE). Descriptive statistics of each variable are featured in Table 1 and Table 2.

Table 1. Descriptive statistics of variables I

\begin{tabular}{lc}
\hline Variable & Quantity/Percentage \\
\hline Gender & 39 \\
Male & 61 \\
Female & \\
Marital Status & 48 \\
Single & 47 \\
Married & 3 \\
Separated & 2 \\
Widowed & \\
Religion & 70 \\
Roman Catholic & 7 \\
Born-Again Christian & 4 \\
Baptist & 3 \\
Protestant-UCCP & 3 \\
Agnostic & 38 \\
Others & 37 \\
Highest Educational Attainment & 3 \\
Bachelor's Degree & 3 \\
Master's Degree & \\
Doctorate Degree & 3 \\
Professional Degree & \\
\hline
\end{tabular}




\begin{tabular}{ll}
\hline Current Academic Position & 21 \\
Lecturer & 35 \\
Instructor & 29 \\
Assistant Professor & 12 \\
Associate Professor & 3 \\
Professor & \\
Part-time/Full-time Status* & 21 \\
Part-time & 79 \\
Full-time & \\
Public University & 34 \\
University of the Philippines Diliman & 26 \\
Bataan Peninsula State University & 14 \\
University of the Philippines Manila & 14 \\
Bicol State College of Applied Sciences and Technology & 7 \\
Quezon City Polytechnic University & 5 \\
Others & 54 \\
Taught Previously in an Educational Institution & 56 \\
Yes & 54 \\
No & \\
\hline
\end{tabular}

Note. *Lecturers are considered working part-time, while the remaining positions are considered working full-time.

Table 2. Descriptive statistics of variables II

\begin{tabular}{llll}
\hline Variable & Mean & Standard Deviation & Range \\
\hline Age & 37.96 & 11.53 & $21-63$ \\
Years of Teaching Experience & 11.57 & 10.33 & .17 (2 months)-39 \\
Number of Students & 139.55 & 104.64 & $12-450$ \\
Number of Different Subjects* & 3.24 & 1.67 & $1-11$ \\
Number of Teaching/Class Hours & 16.85 & 9.80 & $3-45$
\end{tabular}

Note. *For example, if a faculty member is currently teaching two classes of Psych 101, a class of Psych 102 and two classes of Psych 103, then he/she is teaching three different subjects (Psych 101, Psych 102 and Psych 103).

\subsection{Materials}

A total of three instruments were included in the content of the survey. The Faculty Stress Index (FSI; Gmelch, Wilke, \& Lovrich, 1984) originally consists of 45 items designed to identify kinds of situations faculty members report as stressful and to assist in the development of strategies in order to aid faculty members in their coping with stress (Gmelch, 1993). The 45 items are divided into five subscales representing the type of stressor:

- The reward and recognition subscale refers to "inadequate rewards, insufficient recognition, and unclear expectations" (Gmelch, 1993, p. 26) in teaching, research and service.

- The time constraints subscale includes insufficient time to prepare for class lessons, attending meetings, heavy workload and others.

- The departmental influence subscale refers to activities involving the department chair, including influencing the chair's decisions, resolving difference with the chair and understanding how the chair evaluates the performance of the faculty.

- The professional identity subscale relates to building faculty reputation and having high self-expectations. 
- The student interaction subscale refers to the interaction between the faculty and the students in teaching, evaluating and advising.

The index was finalized after pilot testing for content validity and clarity with a group of faculty members. Item reliability assessment yielded a 2-week test-retest reliability value of .83 (Gmelch et al., 1984). For this study, only 31 items (Note 3) were included in the survey as these items (with their high loadings of at least .40) served as the basis in determining the subscales of the said index. These items were rated in a 5-point Likert scale from "very slight pressure" to "excessive pressure" with an option for "not applicable" if participants did not feel that the particular item contributed to their stress. The total faculty stress score was determined by getting the sum of ratings to all 31 items. A high score in the total faculty stress score is indicative of a high degree of faculty stress.

The Teacher Satisfaction Scale (TSS; Ho \& Au, 2006) measures the overall satisfaction of teachers in their profession. This consists of five statements in a 5-point Likert scale from "strongly disagree" to "strongly agree". The total faculty (job) satisfaction score was determined by getting the sum of ratings to all five statements. A high score in the total faculty satisfaction score suggests a high degree of faculty satisfaction. Ho and $\mathrm{Au}$ (2006) found a Cronbach's alpha of .77 and a 2-week test-retest reliability value of .76 for their sample of teachers. They also reported favorable convergent, criterion and incremental validities. For this study, the word "faculty" was added in the phrasing of all five statements as it is mostly used when pertaining to university faculty members.

The Brief RCOPE (Pargament et al., 2011) measures both positive and negative religious coping with major life stressors. Developed based on Pargament's (1997) theory on religious coping, it has helped increased the knowledge as to how religion plays a crucial role in an individual's situation of crisis and trauma. It consists of 14 items (seven for each subscale/type of religious coping) in a 4-point Likert scale from "not at all" to "a great deal". The total score for each subscale was determined by getting the sum of ratings to that subscale. The higher the subscale score, the more a person uses that type of religious coping. Based on several studies featuring diverse samples, Pargament et al. (2011) reported good internal consistency for the instrument with median Cronbach's alphas of .92 and .81 for the positive religious coping subscale and the negative religious coping subscale respectively. The authors also found some support for concurrent and incremental validities and initial evidence for predictive validity, sensitivity to change and validity among different cultural and religious groups.

Demographic questions like age, gender and marital status and education-related questions such as number of students being taught/handled and number of teaching/class hours per week were also included in the survey.

\subsection{Procedure}

Considering the researcher's limitations in contacting faculty members at different Philippine public universities, participant recruitment was performed by giving the survey to individuals (mostly faculty members known by the researcher) who then provided the survey to faculty members from among their acquaintances. This was also done to ensure that the sample was not limited to faculty members of the researcher's home university. Participants were given the option to answer the survey in either online or paper format depending on which was more convenient for them. Whether it was an online or paper format, the survey contained in its first portion a consent form. Participants were provided with a brief description of the study, were assured about confidentiality of the information provided and were informed of their right to withdraw from the study. Before proceeding to the main portion of the survey, participants first answered two screening questions to ensure that they met the study's participant requirements. In the last portion of the survery, participants were given an option to provide their emails if they were interested to receive a summary of the results. Participants' responses were not included in all analyses if they (1) did not meet the study's participant requirements (i.e., answered a "no" in any of the two screening questions) or (2) did not answer much of the questions in the survey (ex. a page for many demographic and education-related questions was left unanswered).

Survey administration and collection took place from October 6, 2016 to November 18, 2016.

\subsection{Data Analysis}

All statistical analyses were performed using the software SPSS Statistics.

The main statistical analysis for this study was multiple regression in order to identify significant predictors of faculty stress considering the 10 variables of interest. Multiple regression analysis was also used to determine if the FSI subscales were significant predictors of job satisfaction. Other statistical analyses such as Pearson correlation analyses and independent-measures t-tests (ex. if there was a significant difference between male and female faculty members in faculty stress) were used to help answer the questions of interest and to supplement the findings of the study. 


\section{Results}

\subsection{Faculty Stress Index}

For the reward and recognition subscale, receiving inadequate salary to meet the financial needs was the area in which participants felt the most pressured with a mean of 2.91. This was followed by the lack of congruency in institutional, departmental and personal goals with a mean of 2.55. The area where participants reported the least pressure was not having clear criteria for evaluation of research and publication activities with a mean of 2.07.

Having job demands which interfere with other personal activities was the most pressured area for the time constraints subscale with a mean of 2.95. This was followed by attending meetings which take up too much time with a mean of 2.87. Being interrupted frequently by telephone calls and drop-in visitors was the area with the least amount of pressure by participants with a mean of 1.56 .

Not knowing how their chair evaluates their performance and lacking personal impact on departmental/institutional decision-making were the two most pressured areas for the departmental influence subscale with means of 2.19 and 2.16 respectively. Resolving differences with their chair, on the other hand, was the least pressured area with a mean of 1.71 .

For the professional identity subscale, the area where participants reported the most pressure was imposing excessively high self-expectations with a mean of 2.96. Next to this was preparing a manuscript for publication with a mean of 2.91. However, securing financial support for their research was the least pressured area with a mean of 1.97 .

Evaluating the performance of students was the most pressured area for the student interaction subscale with a mean of 2.61. This was followed by teaching/advising inadequately prepared students with a mean of 2.59 . Participants reported the least pressure in resolving differences with students with a mean of 2.01.

Overall, imposing excessively high self-expectations $(M=2.96)$ and having job demands which interfere with other personal activities $(M=2.95)$ were the top two most pressured areas by faculty members who participated in this study. Total faculty stress scores ranged from 18 to 141 out of a possible 155 . With a mean of 74.19 ( $S D=$ 24.55), faculty members, in general, felt slight to moderate pressure when dealing with these stressors. Descriptive statistics, including reliability analysis (Cronbach's alpha), of each FSI subscale are featured in Table 3.

Table 3. Descriptive statistics for Faculty Stress Index

\begin{tabular}{lcccccc}
\hline Subscale & Number of Items & Total Possible Score & Mean & Standard Deviation & Range & Cronbach's $\alpha$ \\
\hline Reward and Recognition & 8 & 40 & 18.67 & 9.27 & $0-38$ & .90 \\
Time Constraints & 10 & 50 & 25.28 & 9.13 & $5-48$ & .86 \\
Departmental Influence & 4 & 20 & 8.02 & 5.05 & $0-19$ & .87 \\
Professional Identity & 4 & 20 & 10.65 & 4.23 & $0-19$ & .61 \\
Student Interaction & 5 & 25 & 11.57 & 4.44 & $4-22$ & .79 \\
Total Faculty Stress Score & 31 & 155 & 74.19 & 24.55 & $18-141$ & .92 \\
\hline
\end{tabular}

\subsection{Teacher Satisfaction Scale}

Total faculty (job) satisfaction scores ranged from 8 to 25 out of a possible 25 . With a mean of $18.12(S D=3.67)$, it can be noted that faculty members, in general, were somewhat satisfied with their jobs. Highest rated statement was "I am satisfied with being a teacher/faculty" with a mean of 3.96, while the lowest rated statement was "My working conditions as a teacher/faculty are excellent" with a mean of 3.24. Using reliability analysis, the Cronbach's alpha of the whole instrument was .76, which is close to the one provided by Ho and $\mathrm{Au}$ (2006).

\subsection{Brief RCOPE}

Total positive religious coping scores ranged from 7 to 28 out of a possible $28(M=20.03 ; S D=5.87)$, while total negative religious coping scores ranged from 7 to 22 out of a possible $28(M=9.50 ; S D=3.72)$. Using a paired-samples t-test, significant differences were found between positive and negative religious coping, $t(99)=$ $16.86, p<.05$. This concludes that faculty members in this study preferred positive religious coping as a strategy to decrease their stress over negative religious coping. Reliability analysis indicated a Cronbach's alpha of .90 for the 
positive religious coping subscale, .84 for the negative religious coping subscale and .86 for the whole instrument, all of which show high reliability.

\subsection{Correlation and Other Analyses}

Table 4 summarizes the correlation values of all interested variables after performing a two-tailed Pearson correlation analysis. To highlight particular correlations, faculty stress had significant positive correlations with part-time/full-time status, $r=+.28, p<.01$, and negative religious coping, $r=+.24, p<.05$. Having higher faculty stress was associated more with having a full-time job. In addition, the more a faculty member used negative religious coping, the more stress one experienced. Faculty stress had a significant negative correlation with job satisfaction, $r=-.24, p<.05$. The higher the job satisfaction, the lower the stress a faculty member experienced. When it comes to the correlations with religious coping, the negative type had a significant negative correlation with gender, $r=-.29, p<.01$, which means that negative religious coping was associated more to males than females. On the other hand, the positive type had significant positive correlations with number of students being taught/handled, $r=.37, p<.01$, number of teaching/class hours per week, $r=.36, p$ $<.01$, and very interestingly negative religious coping, $r=.21, p<.05$.

Independent-measures t-test confirmed a significant difference between male and female faculty members in negative religious coping, $t(98)=3.01, p<.05$, with males $(M=10.85, S D=4.21)$ having a higher score than females $(M=8.64, S D=3.10)$. No significant differences were reported for job satisfaction, $t(98)=-1.68$, $p>.05$, positive religious coping, $t(98)=-1.09, p>.05$, and faculty stress, $t(98)=1.22, p>.05$. The test also confirmed a significant difference between part-time and full-time faculty members in faculty stress, $t(98)=$ $-2.87, p<.05$, with part-time faculty members $(M=61.00, S D=23.63)$ having a lower stress score than full-time faculty members $(M=77.70, S D=23.71)$. No significant differences were reported for job satisfaction, $t(98)=-.97, p>.05$, positive religious coping, $t(98)=-1.29, p>.05$, and negative religious coping, $t(98)=.76$, $p>.05$.

Table 4. Correlations of all variables

\begin{tabular}{lccccccccccc}
\hline & Gender & Age & Year & Part/Full-time & Students & Subjects & Hours & Satisfaction & Positive & Negative & Stress \\
\hline Gender & 1 & .05 & .06 & -.01 & .10 & .02 & -.06 & .16 & .11 & $-.29^{* *}$ & -.12 \\
Age & .05 & 1 & $.84^{* *}$ & $.32^{* *}$ & .01 & .15 & .07 & .17 & .09 & .10 & -.09 \\
Year & .06 & $.84^{* *}$ & 1 & $.39^{* *}$ & .02 & .16 & .13 & $.26^{* *}$ & .15 & .10 & .00 \\
Part/Full-time & -.01 & $.32^{* *}$ & $.39 * *$ & 1 & -.05 & $.21^{*}$ & .16 & .10 & .13 & -.08 & $.28^{* *}$ \\
Students & .10 & .01 & .02 & -.05 & 1 & $.26^{* *}$ & $.41^{* *}$ & .05 & $.37^{* *}$ & -.03 & .08 \\
Subjects & .02 & .15 & .16 & $.21^{*}$ & $.26^{* *}$ & 1 & $.27^{* *}$ & .18 & .06 & -.19 & .01 \\
Hours & -.06 & .07 & .13 & .16 & $.41^{* *}$ & $.27 * *$ & 1 & .17 & $.36^{* *}$ & .04 & -.03 \\
Satisfaction & .16 & .17 & $.26^{* *}$ & .10 & .05 & .18 & .17 & 1 & .01 & -.18 & $-.24^{*}$ \\
Positive & .11 & .09 & .15 & .13 & $.37^{* *}$ & .06 & $.36^{* *}$ & .01 & 1 & $.21^{*}$ & .10 \\
Negative & $-.29 * *$ & .10 & .10 & -.08 & -.03 & -.19 & .04 & -.18 & $.21^{*}$ & 1 & $.24^{*}$ \\
Stress & -.12 & -.09 & .00 & $.28^{* *}$ & .08 & .01 & -.03 & $-.24 *$ & .10 & $.24 *$ & 1 \\
\hline
\end{tabular}

Note. Year = years of teaching experience; Part/Full-time $=$ part-time/full-time status; Students = number of students; Subjects = number of different subjects; Hours $=$ number of teaching/class hours; Satisfaction $=$ job satisfaction; Positive $=$ positive religious coping; Negative $=$ negative religious coping; Stress = faculty stress.

Coding of gender: $0=$ male and $1=$ female; Coding of part/full-time: $0=$ part-time and $1=$ full-time.

$* p<.05, * * p<.01$.

\subsection{Multiple Regression Analyses}

Results of the multiple regression analysis for faculty stress are presented here. Model 1, consisting of all demographic variables (gender, age, year and part-time/full-time status), showed significance. This means that the model was significantly better in predicting faculty stress differences than the mean. In this model, the variable part-time/full-time status was only significant. Model 2, consisting of all demographic variables, number of 
students, number of different subjects, number of teaching/class hours and job satisfaction, also showed significance with part-time/full-time status, age and job satisfaction as significant predictors. Model 3, consisting of all interested predictors, also showed significance with part-time/full-time status, age, job satisfaction and negative religious coping as significant predictors. Participants who were working full-time experienced more stress than those who were working part-time by around 23 points in the stress score. As the age of the participants increased, the stress score decreased by around a point. The more satisfied they were with their job, the less stress they were by around a point in the stress score. Finally, the more they used negative religious coping, the greater the stress score by around 2 points. Model 3 had the highest adjusted $\mathrm{R}^{2}$ out of all the indicated models. Statistics of each model and predictor are included in Table 5 .

Table 5. Predictors of faculty stress

\begin{tabular}{|c|c|c|c|c|c|c|c|c|c|}
\hline \multirow[b]{2}{*}{ Variable } & \multicolumn{3}{|c|}{ Model 1} & \multicolumn{3}{|c|}{ Model 2} & \multicolumn{3}{|c|}{ Model 3} \\
\hline & B & ß & $95 \% \mathrm{CI}$ & B & $\beta$ & $95 \% \mathrm{CI}$ & B & ß & $95 \% \mathrm{CI}$ \\
\hline Gender & -5.68 & -.11 & {$[-15.22,3.85]$} & -5.27 & -.10 & {$[-14.75,4.20]$} & -1.74 & -.04 & {$[-11.56,8.07]$} \\
\hline Age & -.65 & -.31 & {$[-1.39, .09]$} & $-.76^{*}$ & -.36 & {$[-1.48,-.04]$} & $-.79 *$ & -.37 & {$[-1.50,-.08]$} \\
\hline Year & .34 & .14 & {$[-.51,1.19]$} & .60 & .25 & {$[-.24,1.45]$} & .48 & .20 & {$[-.35,1.32]$} \\
\hline Part/Full-time & $19.17 *$ & .32 & {$[6.78,31.57]$} & $21.08 *$ & .35 & {$[8.73,33.44]$} & $23.13 *$ & .39 & {$[10.86,35.39]$} \\
\hline Students & - & - & - & .04 & .18 & {$[-.01, .09]$} & .04 & .19 & {$[-.01, .09]$} \\
\hline Subjects & - & - & - & -.28 & -.02 & {$[-3.22,2.66]$} & .45 & .03 & {$[-2.48,3.39]$} \\
\hline Hours & - & - & - & -.33 & -.13 & {$[-.86, .20]$} & -.39 & -.15 & {$[-.92, .15]$} \\
\hline Satisfaction & - & - & - & $-1.60 *$ & -.24 & {$[-2.93,-.28]$} & $-1.32 *$ & -.20 & {$[-2.63,-.00]$} \\
\hline Positive & - & - & - & - & - & - & -.03 & -.01 & {$[-.92, .86]$} \\
\hline Negative & - & - & - & - & - & - & $1.70^{*}$ & .26 & {$[.34,3.06]$} \\
\hline $\mathrm{R}^{2}$ & \multicolumn{3}{|c|}{.13} & \multicolumn{3}{|c|}{.22} & \multicolumn{3}{|c|}{.27} \\
\hline Adjusted $\mathrm{R}^{2}$ & \multicolumn{3}{|c|}{.09} & \multicolumn{3}{|c|}{.15} & \multicolumn{3}{|c|}{.19} \\
\hline F-ratio & \multicolumn{3}{|c|}{$3.58^{*}$} & \multicolumn{3}{|c|}{$3.21 *$} & \multicolumn{3}{|c|}{$3.34 *$} \\
\hline
\end{tabular}

Note. $\mathrm{B}=$ unstandardized coefficient; $\beta=$ standardized/beta coefficient; $\mathrm{CI}=$ confidence interval; Year $=$ years of teaching experience; Part/Full-time $=$ part-time/full-time status; Students = number of students; Subjects $=$ number of different subjects; Hours $=$ number of teaching/class hours; Satisfaction $=$ job satisfaction; Positive $=$ positive religious coping; Negative $=$ negative religious coping.

Coding of gender: $0=$ male and $1=$ female; Coding of part/full-time: $0=$ part-time and $1=$ full-time.

$* p<.05$.

A stepwise regression analysis was also performed. Results confirmed that the model with part-time/full-time status ( $\mathrm{B}=22.95, t=4.00, p<.05)$, age $(\mathrm{B}=-.44, t=-2.12, p<.05)$, job satisfaction $(\mathrm{B}=-1.28, t=-2.04, p$ $<.05)$ and negative religious coping $(\mathrm{B}=1.67, t=2.71, p<.05)$ had a better predictor performance than Model 3 with just a .01 difference in the adjusted $\mathrm{R}^{2}(F=7.08, p<.05)$.

Another multiple regression analysis was performed with job satisfaction as the dependent variable and the FSI subscales as predictors. The overall model did not indicate any significance (adjusted $\mathrm{R}^{2}=.04, F=1.89, p>.05$ ) with all subscales showing no significance. However, significant correlations (though low in effect size) were found between job satisfaction and both the reward and recognition subscale, $r=-.26, p<.05$, two-tails, and the departmental influence subscale, $r=-.23, p<.01$, two-tails. Statistics of each subscale are presented in Table 6 . 
Table 6. Predictors of job satisfaction

\begin{tabular}{lcccc}
\hline \multicolumn{1}{c}{ Variable } & $\mathrm{B}$ & $\beta$ & $95 \%$ CI & Significance \\
\hline Reward and Recognition & -.08 & -.19 & {$[-.21, .06]$} & .27 \\
Time Constraints & .07 & .17 & {$[-.05, .19]$} & .27 \\
Departmental Influence & -.08 & -.10 & {$[-.32, .17]$} & .54 \\
Professional Identity & -.14 & -.16 & {$[-.36, .07]$} & .19 \\
Student Interaction & -.06 & -.07 & {$[-.27, .16]$} & .61 \\
\hline
\end{tabular}

Note . $\mathrm{B}=$ unstandardized coefficient, $\beta=$ standardized/beta coefficient, $\mathrm{CI}=$ confidence interval.

$* p<.05$.

\section{Discussion}

Based on the performed multiple regression analysis, four predictors were significant to faculty stress among the participants: part-time/full-time status, age, job satisfaction and negative religious coping. The following findings are made in relation to the four significant predictors. Starting off with the first two mentioned predictors, although correlation analysis revealed that part-time/full-time status and age were positively correlated with each other $(r=+.32, p<.01$, two-tails), multiple regression analysis revealed opposite effects for stress levels: full-time faculty members had higher stress levels than part-time faculty members, but stress levels decreased as faculty members got older. With opposing results from the two analyses, the researcher investigated on how age became a significant predictor of faculty stress. Table 7 presents two scenarios when certain variables were entered into the multiple regression analysis.

Table 7. Two scenarios (Unstandardized coefficients and significance values)

\begin{tabular}{lcccc}
\hline & \multicolumn{2}{c}{ Scenario A } & \multicolumn{2}{c}{ Scenario B } \\
\cline { 2 - 5 } Variable & Model 1A & Model 2A & Model 1B & Model 2B \\
\hline Gender & $-3.72(.43)$ & $-3.82(.42)$ & $-5.68(.24)$ & $-3.82(.42)$ \\
Age & $-.34(.11)$ & $-.74(.04)^{*}$ & $-.65(.08)$ & $-.74(.04)^{*}$ \\
Part/Full-time & $21.08(.00)^{*}$ & $19.14(.00)^{*}$ & $19.17(.00)^{*}$ & $19.14(.00)^{*}$ \\
Satisfaction & $-1.54(.02)^{*}$ & $-1.72(.01)^{*}$ & - & $-1.72(.01)^{*}$ \\
Year & - & $.57(.18)$ & $.34(.44)$ & $.57(.18)$
\end{tabular}

Note. Significance values are in parenthesis. Part/Full-time $=$ part-time/full-time status; Satisfaction $=$ job satisfaction; Year $=$ years of teaching experience.

Coding of gender: $0=$ male and $1=$ female, Coding of part/full-time: $0=$ part-time and $1=$ full-time.

${ }^{*} p<.05$.

For Scenario A, when the variables gender, age, part-time/full-time status and job satisfaction were entered into the analysis (Model 1A), both part-time/full-time status and job satisfaction were significant predictors of faculty stress. But when the variable years of teaching experience was added (Model 2A), age also became a significant predictor. This can be attributed to the very strong significant positive correlation between age and year, $r=+.84$, $p<.01$, two-tails. For Scenario B, when the variables gender, age, part-time/full-time status and year were entered into the analysis (Model 1B), the latter variable was the only one significant to predict faculty stress. However, when job satisfaction was added (Model 2B), age and job satisfaction also became significant predictors. This can be associated to the significant correlation between year and job satisfaction, $r=+.26, p$ $<.01$, two-tails. Considering the two scenarios and the correlations of these variables, a possible contributor as to how age became a significant predictor of faculty stress is the age-year-job satisfaction relationship. The weak positive correlation between age and part-time/full-time status may be overpowered by both the very strong significant positive correlation between age and year and the significant positive correlation between year and job satisfaction. Age was not significant at first, but because of its connection with job satisfaction via year, its 
strength to predict faculty stress increased. The said relationship was also confirmed based on the collinearity diagnostics. As the highest variance proportions for age, year and job satisfaction were associated with the same dimensions/eigenvalues, this indicated multicollinearity, or that the three variables were intercorrelated.

The result for part-time/full-time status is contrary to the results provided by Greene et al. (2008) and Gappa (1987) that part-time faculty members experience more stress than full-time faculty members, but in line with the findings provided by Gmelch (1993) and Drakich et al. (2012). The latter research reasoned that full-time faculty members are expected to spend more hours to teach to a great number of students (including having a class with the largest possible number of students) and to create outputs related to the areas of service and research. The result for age supports the findings of Lindholm and Szelényi (2009) and Gmelch et al. (1986) as younger faculty feel greater pressure to show their competencies in different aspects of their academic work, especially when competition for academic promotion is extremely intense. Furthermore, younger faculty feel more stress as they face the challenge of balancing their personal and professional commitments.

Stress levels of faculty members also increased as their satisfaction levels decreased. As reported earlier, though the subscales of the FSI were not significant predictors of job satisfaction, correlations were found for both reward and recognition and departmental influence subscales. Time constraints and student interaction subscales, as earlier hypothesized, did not show significant correlations with job satisfaction. Considering the current situation of the lack of financial resources allocated to Philippine public universities, this confirms the theory of Herzberg, Mausner, and Snyderman (1959) that recognition, whether intrinsic (ex. approval by peers and institution) or extrinsic (ex. salary, extra resources), is a crucial component that positively influences satisfaction in any job. Departmental influence is also crucial as it influences how a faculty member evaluates relationships with departmental/institutional decision-makers and thus job satisfaction (Drakich et al., 2012; Bentley, Coates, Dobson, Goedegebuure, \& Meek, 2013).

When it comes to religious coping, faculty members preferred positive religious coping as a strategy to decrease their stress more than negative religious coping. In addition, negative religious coping increased the stress levels of faculty members based on multiple regression analysis. This shows that Filipino faculty members often use religiosity as a source of strength and comfort in their way of coping with stress. This also supports the findings of Pargament et al. (1998) and Ano and Vasconcelles (2005) that negative religious coping is associated to negative psychological adjustment to stress. Religiosity, therefore, is "an important personal factor influencing appraisal by enabling individuals to evaluate the event in a more positive and purposeful light" (Chun, Moos, \& Cronkite, 2006, p. 39). An interesting result from the performed correlation analysis is that positive religious coping had a significant positive (though not strong) association with negative religious coping. This means that faculty members may use positive and negative religious coping concurrently. While a faculty member may regularly engage in positive religious coping, this does not rule out the possibility of facing religious struggle and doubt. This matter was earlier highlighted by Fitchett et al. (2004), "Positive religious coping is not the opposite of negative religious coping" (p. 191). In addition, faculty members may resort to negative religious coping as relying on God or the church solely may not be enough to cope in some of their academic-related stresses. Faculty members may also turn to other problem-focused and emotion-focused coping strategies, such as active coping, social support and positive interpretation (Carver, Scheir, \& Weintraub, 1989).

\section{Limitations and Directions for Future Research}

Despite the results presented, a number of limitations were noted throughout the study. First, it only considered 10 factors as possible significant predictors of faculty stress given the generally small number of participants in this study. There are still many factors that may be significant. These include marital status, academic position (ex. instructor, associate professor), if the faculty member is still studying, number of different subjects usually required to teach/handle in a semester and number of teaching/class hours per week usually required in a semester. Future research should also study these factors as possible significant predictors of faculty stress.

Second, a faculty member's stress and job satisfaction levels may not be constant all throughout the semester as they were evaluated on a particular day/period. For instance, a faculty member's stress and job satisfaction levels during midterms week may be different from his/her stress and job satisfaction levels during a regular week. Future research should consider evaluating all participants on a particular day/period, most preferably during a week that is less stressful for them.

Third, the study sample may not best represent all public university faculty members in the Philippines since the sample size was generally small, and around $80 \%$ of the participants were faculty members from public universities located in Metro Manila. The small sample size can be attributed to the low response rate. Future 
research should include a larger population, possibly getting participants from each region of the Philippines, to make it more representative.

Finally, it is important to consider that the university's culture, though not examined in this study, can greatly affect the faculty members' stress and job satisfaction levels. Additional research is required to examine aspects of the university's culture that may impact their experiences of stress and coping.

This study can be useful in industrial-organizational psychology and school psychology. Psychologists from these fields can provide recommendations to university/department/institute leaders on possible ways to help decrease the stress levels of their faculty and improve their perceptions about their working environment. Clinical psychologists can also strategize psychotherapies and other clinical interventions (ex. workshops) that can decrease their stress levels and thus improve their psychological well-being. As the reward and recognition subscale of the FSI was significantly correlated with job satisfaction, this could also be addressed to CHED and other related government agencies in order to provide more support on the necessity of additional budget for public university faculty members.

\section{Conclusion}

The study's aims were to assess the stress levels of public university faculty members in the Philippines and to identify significant predictors of faculty stress. In addition, this study explored any significant associations between the FSI scales and job satisfaction and significant associations between the two types of religious coping and faculty stress. Based on the responses of 100 participants, faculty members generally felt slight to moderate pressure when dealing with different stressors. Multiple regression analysis also revealed part-time/full-time status, age, job satisfaction and negative religious coping as significant predictors of faculty stress. Stressors related to reward and recognition and departmental influence showed significant negative correlations with job satisfaction. Finally, though faculty members preferred positive religious coping over negative religious coping, results suggested that faculty members may use positive and negative religious coping simultaneously.

\section{Acknowledgments}

The researcher wishes to express his deepest appreciation and thanks to Dr. Lynna Marie Sycip, chairperson of the Department of Psychology, University of the Philippines Diliman, for her guidance during the research paper process. The researcher also wishes to express his warmest gratitude to his colleagues and friends for their help and support in this research.

\section{References}

Abbas, S. G., \& Roger, A. (2013). The impact of work overload and coping mechanisms on different dimensions of stress among university teachers. @ GRH 2013/3 (n 8), 93-118. https://doi.org/10.3917/grh.133.0093

Akbar, A., \& Akhter, W. (2011). Faculty stress at higher education: A study of the business schools of Pakistan. International Journal of Social, Behavioral, Educational, Economic, Business and Industrial Engineering, 5(1), 93-97. Retrieved from http://waset.org/publications/15575/faculty-stress-at-higher-education-a-study-on-the-business-schools-of-p akistan

Akkoc, R. (2015, April 13). Mapped: These are the world's most religious countries. Retrieved from http://www.telegraph.co.uk/news/worldnews/11530382/Mapped-These-are-the-worlds-most-religious-count ries.html

Ano, G. G., \& Vasconcelles, E. B. (2005). Religious coping and psychological adjustment to stress. Journal of Clinical Psychology, 61, 461-480. https://doi.org/10.1002/jclp.20049

Arnold, G. L., Trice, A. G., Rosevear, S. G., \& McKinnon, S. A. (1996, November). Faculty stress: The influence of institutional characteristics. Paper presented at the Annual Meeting of the Association for the Study of Higher Education, Memphis, TN.

Bentley, P. J., Coates, H., Dobson, I. R., Goedegebuure, L., \& Meek, V. L. (2013). Factors associated with job satisfaction amongst Australian university academics and future workforce implications. In P. J. Bentley, H. Coates, I. R. Dobson, L. Goedegebuure, \& V. L. Meek (Eds.), Job satisfaction around the academic world (pp. 29-53). New York, NY: Springer.

Betonio, J. R. (2015). Stress factors and the teaching performance of the college faculty. International Journal of Social Science and Humanity, 5, 651-655. https://doi.org/10.7763/IJSSH.2015.V5.534 
Blix, A. G., Cruise, R. J., Mitchell, B. M., \& Blix, G. G. (1994). Occupational stress among university teachers. Educational Research, 36, 157-169. https://doi.org/10.1080/0013188940360205

Brewer, E., \& McMahan-Landers, J. (2013). The relationship between job stress and job satisfaction among industrial and technical teacher educators. Journal of Career and Technical Education, 20(1), 37-50. https://doi.org/10.21061/jcte.v20i1.622

Carver, C. S., Scheier, M. F., \& Weintraub, J. K. (1989). Assessing coping strategies: A theoretically based approach. Journal of Personality and Social Psychology, 56, 267-283. https://doi.org/10.1037/0022-3514.56.2.267

Chun, C.-A., Moos, R. H., \& Cronkite, R. C. (2006). Culture: A fundamental context for the stress and coping paradigm. In P. T. P. Wong, \& L. C. J. Wong (Eds.), Handbook of multicultural perspectives on stress and coping (pp. 29-53). New York, NY: Springer.

Chung, C. E. E. (2011). Job stress, mentoring, psychological empowerment, and job satisfaction among nursing faculty (Doctoral dissertation). Retrieved from UNLV Theses, Dissertations, Professional Papers, and Capstones.

Colacion-Quiros, H., \& Gemora, R. B. (2016). Causes and effects of stress among faculty members in a state university. Asia Pacific Journal of Multidisciplinary Research, 4(1), 18-27. Retrieved from http://www.apjmr.com/wp-content/uploads/2016/03/APJMR-2016.4.1.04.pdf

Commission on Higher Education. (n.d.). Higher education date infographics. Retrieved from http://www.ched.gov.ph/central/page/higher-education-indicators-1

Conchada, M. I. P., \& Zamudio, I. G. C. (2013). The cost efficiency of state universities and colleges in the Philippines. Philippine Review of Economics, 50(2), 85-106. Retrieved from http://www.academia.edu/7357413/The_cost_efficiency_of_state_universities_and_colleges_in_the_Philip pines

De Cadiz, G. B., \& Sonon, H. E. (2012). Levels of confidence and stress among faculty members of Eastern Visayas State University-Carigara Campus. https://doi.org/10.13140/2.1.5076.6085

Dela Peña, S. C. III. (2011). Spirituality and work stress of teacher education institution faculty in Cagayan de Oro City, Philippines. IAMURE International Journal of Multidisciplinary Research, 2, 1-17. https://doi.org/10.7718/iamure.v2i1.56

Donovan, R. A. (2012). Perceptions of stress, workload, and job satisfaction among HSS faculty: Executive summary. $\quad$ Retrieved http://dean.hss.kennesaw.edu/docs/tea-terrace_donovan-06-12_exec-summary.pdf

Drakich, J., Maticka-Tyndale, E., Farooqi, A., Fiki, C., Gaspard, A., Hutchings, G., ... Zhang, A. (2012). Faculty work life and job satisfaction: University of Windsor, 2012. Retrieved from http://web4.uwindsor.ca/units/researchEthicsBoard/.../FINAL\%20REPORT\%2008-31.docx

Easthope, C., \& Easthope, G. (2000). Intensification, extension and complexity of teachers' workload. British Journal of Sociology of Education, 21, 43-58. https://doi.org/10.1080/01425690095153

Ereno, J. R., Andrade, K. M., Miyauchi, S. I., Salinda, R., Arevalo, R. R., \& Reyes, J. (2014). Encountering and countering work stress: A multivariate analysis of the occupational stress and coping mechanisms of fast food restaurant personnel in the Philippines. European Scientific Journal, 10(8), 148-158. Retrieved from http://eujournal.org/index.php/esj/article/viewFile/3012/2838

Fitchett, G., Murphy, P. E., Kim, J., Gibbons, J. L., Cameron, J. R., \& Davis, J. A. (2004). Religious struggle: Prevalence, correlates, and mental health risks in diabetic, congestive hear failure, and oncology patients. International Journal of Psychiatry in Medicine, 34, 179-196. https://doi.org/10.2190/UCJ9-DP4M-9C0X-835M

Gappa, J. M. (1987). The stress-producing working conditions of part-time faculty. New Directions for Teaching and Learning, 1987(29), 33-42. https://doi.org/10.1002/tt.37219872906

Gartia, R., \& Sharma, S. (2013). Stress among teacher educators from self-financing colleges of education. International Journal of Research Pedagogy and Technology in Education and Movement Sciences, 1(3), 221-232. Retrieved from http://www.ijems.net/3\%20IJEMSP22.pdf 
Gillespie, N. A., Walsh, M., Winefield, A. H., Dua, J., \& Stough, C. (2001). Occupational stress in universities: Staff perceptions of the causes, consequences and moderators of stress. Work and Stress, 15, 53-72. https://doi.org/10.1080/02678370117944

Gmelch, W. H. (1993). Coping with faculty stress. Newbury Park, CA: Sage. https://doi.org/10.4135/9781483326313

Gmelch, W. H., Wilke, P. K., \& Lovrich, N. P. (1984, April). Factorial dimensions of faculty stress. Paper presented at the Annual Meeting of the American Educational Research Association, New Orleans, LA. Abstract retrieved from http://archive.org/details/ERIC_ED245648

Gmelch, W. H., Wilke, P. K., \& Lovrich, N. P. (1986). Dimensions of stress among university faculty: Factor-analytic results from a national study. Research in Higher Education, 24, 266-286. https://doi.org/10.1007/BF00992075

Greene, H. C., O’Connor, K., Good, A., Ledford, C., Peel, B., \& Zhang, G. (2008). Building a support system toward tenure: Challenges and needs of tenure-track faculty in colleges of education. Mentoring and Tutoring: Partnership in Learning, 16, 429-447. https://doi.org/10.1080/13611260802433791

Gupta, V., Rao, E., \& Mukherjee, R. (2015). Occupational stress amongst faculty members: A review of literature. International Journal of Research and Development-A Management Review, 4(2), 18-27. Retrieved from http://www.irdindia.in/journal_ijrdmr/pdf/vol4_iss2/3.pdf

Hart, J. L., \& Cress, C. M. (2009). Are women faculty just "worrywarts?" Accounting for gender differences in self-reported stress. In D. R. Buckholdt, \& G. E. Miller (Eds.), Faculty stress (pp. 174-192). New York, NY: Routledge.

Herzberg, F., Mausner, B., \& Snyderman, B. B. (1959). The motivation to work. New York, NY: John Wiley and Sons.

Ho, C. L., \& Au, W. T. (2006). Teaching Satisfaction Scale: Measuring job satisfaction of teachers. Educational and Psychological Measurement, 66, 172-185. https://doi.org/10.1177/0013164405278573

Inasoria, R. D. C. (2014). Effects of profile, religiosity and job attitude on the job performance of the Philippine National Police: The case of Bulacan province. Asia Pacific Journal of Multidisciplinary Research, 2(5), 22-32. Retrieved from http://www.apjmr.com/wp-content/uploads/2014/09/APJMR-2014-2-119.pdf

Iqbal, A., \& Kokash, H. (2011). Faculty perception of stress and coping strategies in a Saudi private university: An exploratory study. International Education Studies, 4(3), 137-149. https://doi.org/10.5539/ies.v4n3p137

Jamison, M. R., \& Enrera, J. A. (2015). Factors affecting work productivity among the female faculty of allied medical health colleges of University of Hail, Saudi Arabia. IOSR Journal of Nursing and Health Science, 4(6), 25-39. Retrieved from http://www.iosrjournals.org/iosr-jnhs/papers/vol4-issue6/Version-5/E04652539.pdf

Jing, L. (2008). Faculty's job stress and performance in the undergraduate education assessment in China: A mixed-methods study. Educational Research and Reviews, 3, 294-300. Retrieved from http://academicjournals.org/journal/ERR/article-full-text-pdf/C079F433395

Kavitha, P. (2012). Organisational role stress among college faculties: An empirical study. Global Management Review, 6(4), 36-50.

Khan, E. A., Aqeel, M., \& Riaz, M. A. (2014). Impact of job stress on job attitudes and life satisfaction in college lecturers. International Journal of Information and Education Technology, 4, 270-273. https://doi.org/10.7763/IJIET.2014.V4.411

Kinman, G. (2001). Pressure points: A review of research on stressors and strains in UK academics. Educational Psychology, 21, 473-492. https://doi.org/10.1080/01443410120090849

Kinman, G., \& Jones, F. (2008). A life beyond work? Job demands, work-life balance, and wellbeing in UK academics. Journal of Human Behavior in the Social Environment, 17, 41-60. https://doi.org/10.1080/10911350802165478

Lindholm, J. A., \& Szelényi, K. (2009). Faculty time stress: Correlates within and across academic disciplines. In D. R. Buckholdt, \& G. E. Miller (Eds.), Faculty stress (pp. 19-40). New York, NY: Routledge.

Loquias, M. M., \& Sana, E. A. (2013). Job satisfaction among faculty members in the colleges of pharmacy in Metro Manila, Philippines. International Journal of Pharmacy Teaching and Practices, 4, 787-792. 
Retrieved from

20M.\%20Loquias \%20et\%20al., \%20dec\%202013.pdf

http://iomcworld.com/ijptp/files/Monet\%

Merchant, Z. A., \& Shastri, S. (2013). Exploring job satisfaction, stress and coping: Strategies employed by engineering faculty. International Journal of Science and Research, 2(10), 72-77. Retrieved from http://www.ijsr.net/archive/v2i10/MDIxMDEzMDQ=.pdf

Muchinsky, P. M. (2007). Psychology applied to work (8th ed.). Belmont, CA: Wadsworth.

Ngohayon, S. L., \& Nangphuhan, J. B. II. (2016). Pushing for globalized higher education in the Philippines: Advances and challenges. In C. S. Collins, M. N. N. Lee, J. N. Hawkins, \& D. E. Neubauer (Eds.), The Palgrave handbook of Asia Pacific higher education (pp. 483-496). New York, NY: Palgrave Macmillan. https://doi.org/10.1057/978-1-137-48739-1_32

O’Laughlin, E. M., \& Bischoff, L. G. (2005). Balancing parenthood and academia: Work/family stress as influenced by gender and tenure status. Journal of Family Issues, 26, 79-106. https://doi.org/10.1177/0192513X04265942

Pargament, K. I. (1997). The psychology of religion and coping: Theory, research and practice. New York, NY: Guilford Press.

Pargament, K. I., Feuille, M., \& Burdzy, D. (2011). The Brief RCOPE: Current psychometric status of a short measure of religious coping. Religions, 2, 51-76. https://doi.org/10.3390/rel2010051

Pargament, K. I., Smith, B. W., Koenig, H. G., \& Perez, L. (1998). Patterns of positive and negative religious coping with major life stressors. Journal for the Scientific Study of Religion, 37, 710-724. https://doi.org/10.2307/1388152

Parveen, M. (2013). Faculty stress in a Saudi government university. International Journal of Humanities and Social Science, $\quad 3(18), \quad 180-192 . \quad$ Retrieved from http://www.ijhssnet.com/journals/Vol_3_No_18_October_2013/19.pdf

Rafeeq, M., \& Harish, P. (2015). Work life balance (WLB) is life-work balance (LWB) an innovative approach on teaching faculties in private rural higher educational institutions. IOSR Journal of Business and Management, $\quad$ 17(4), 22-30. $\quad$ Retrieved from http://iosrjournals.org/iosr-jbm/papers/Vol17-issue4/Version-4/D017442230.pdf

Reevy, G. M., \& Deason, G. (2014). Predictors of depression, stress, and anxiety among non-tenure track faculty. Frontiers in Psychology, 5, 1-17. https://doi.org/10.3389/fpsyg.2014.00701

Schuldt, B. A., \& Totten, J. W. (2008). An exploratory study: Business faculty and the Faculty Stress Index. Proceedings of the Allied Academies, 15(2), 128-133. Retrieved from http://citeseerx.ist.psu.edu/viewdoc/download?doi=10.1.1.519.4949\&rep=rep1\&type=pdf

Slišković, A., \& Maslić Seršić, D. (2011). Work stress among university teachers: Gender and position differences. Archives of Industrial Hygiene and Toxicology, 62, 299-307. https://doi.org/10.2478/10004-1254-62-2011-2135

Thorsen, E. J. (1996). Stress in academe: What bothers professors? Higher Education, 31, 471-489. https://doi.org/10.1007/BF00137127

Veena, G., Pushpalatha, K., \& Mallaiah, T. Y. (2016). Professional stress among faculty members of Mangalore University: A study. International Journal of Scientific Research and Management, 4, 4279-4286. https://doi.org/10.18535/ijsrm/v4i6.10

Wiggins, K. (2015, June 25). Teaching is among the "top three most stressed occupations". Retrieved from http://www.tes.com/news/school-news/breaking-news/teaching-among-top-three-most-stressed-occupations

Winefield, A. H., \& Jarrett, R. (2001). Occupational stress in university staff. International Journal of Stress Management, 8, 285-298. https://doi.org/10.1023/A:1017513615819 


\section{Notes}

Note 1. Public universities and colleges/higher education institutions in the Philippines include state universities and colleges (SUCs), SUC's satellite campuses, local colleges and universities and others.

Note 2. "Current semester" refers to the First Semester of Academic Year (AY) 2016-2017.

Note 3. Researches such as Parveen (2013), Iqbal and Kokash (2011) and Jing (2008) also used the FSI as the instrument of choice but (1) did not use all 45 items, (2) included items that are not in the original FSI, or (3) categorized items into a different subscale/type of stressor.

\section{Copyrights}

Copyright for this article is retained by the author(s), with first publication rights granted to the journal.

This is an open-access article distributed under the terms and conditions of the Creative Commons Attribution license (http://creativecommons.org/licenses/by/4.0/). 